\title{
From pioneering to implementing automated blood pressure measurement in clinical practice: Thomas Pickering's legacy
}

\author{
Katarzyna Stolarz-Skrzypek ${ }^{a, b}$, Lutgarde Thijs ${ }^{a}$, Barbara Wizner ${ }^{c}$, \\ Tom Richart ${ }^{\mathrm{a}, \mathrm{d}}$, Gbenga Ogedegbe ${ }^{\mathrm{e}}$, Yan Lif ${ }^{\mathrm{f}, \mathrm{g}}$, Tine W. Hansen ${ }^{\text {h,i }}$, José Boggia ${ }^{\mathrm{j}}$, \\ Masahiro Kikuya ${ }^{k}$, Tatiana Kuznetsovaa ${ }^{a}$, Jiguang Wang ${ }^{f}$, Empar Lurbe', \\ Yutaka Imaik, Kalina Kawecka-Jaszcz ${ }^{\mathrm{b}}$ and Jan A. Staessen ${ }^{\mathrm{a}, \mathrm{d}}$
}

\begin{abstract}
Thomas G. Pickering spent most of his scientific career in carrying out research on clinical hypertension and blood pressure (BP) measurement. In our review of Pickering's seminal work, we first focused on white-coat hypertension and masked hypertension, two terms that he had introduced. Next, we highlighted the early publications of Pickering on diurnal BP variability and on the clinical application of self-measured BP. Pickering's work inspired many investigators worldwide and constituted a solid basis for further research. Pickering's original ideas led to algorithms for risk stratification involving white-coat hypertension and masked hypertension, diurnal BP variability, and self-measured BP. Recent studies validated Pickering's observations in terms of cardiovascular outcome and bridged the path from concept to application in clinical practice. Blood Press Monit 15:72-81 (c) 2010 Wolters Kluwer Health | Lippincott Williams \& Wilkins.
\end{abstract}

Blood Pressure Monitoring 2010, 15:72-81

\section{Introduction}

Thomas G. Pickering spent his scientific career in carrying out research on behavioral cardiovascular medicine, clinical hypertension, and blood pressure (BP) measurement. His work inspired many investigators worldwide and stimulated research on BP measurement, particularly on the clinical application of $24-\mathrm{h}$ ambulatory $\mathrm{BP}$ monitoring (ABPM) and the self-measurement of BP at home.

In 2002, Thomas G. Pickering wrote 'The addition of ABPM to conventional clinic measurements for defining $\mathrm{BP}$ status in clinical practice has added a new complexity to the process, because the separation of normotension and hypertension can be assessed independently by each of the two methods' [1]. The two groups of patients that arise from this classification and require special attention are individuals with white-coat hypertension and those with masked hypertension. Other focal points in Pickering's work were BP variability [2] and the assessment of $\mathrm{BP}$ by self-measurement [3-5].

\section{White-coat hypertension}

\section{First studies on white-coat hypertension}

In his study, which was published in Journal of The American Medical Association in 1988 [6], Thomas Pickering 1359-5237 (C) 2010 Wolters Kluwer Health | Lippincott Williams \& Wilkins
Keywords: blood pressure, diurnal blood pressure variability, masked hypertension, self-measured blood pressure, white-coat hypertension

aStudies Coordinating Centre, Division of Hypertension and Cardiac Rehabilitation, Department of Cardiovascular Diseases, University of Leuven Leuven, Belgium, ${ }^{b}$ First Department of Cardiology and Hypertension, 'Department of Internal Medicine and Gerontology, Jagiellonian University, Kraków, Poland, 'Department of Epidemiology, Maastricht University, Maastricht, The Netherlands, ${ }^{\ominus}$ Center for Healthful Behavior Change, New York University School of Medicine, New York, USA, ${ }^{\dagger}$ Center for Epidemiological Studies and Clinical Trials, ${ }^{9}$ Center for Vascular Evaluation, Ruijin Hospital, Shanghai Jiaotong

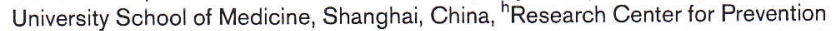
and Health, Department of Clinical Physiology, Faculty of Health Sciences, Hvidovre University Hospital, 'Department of Clinical Physiology and Nuclear Medicine, Copenhagen University Hospital, Copenhagen, Denmark, 'Centro de Nefrologia and Departamento de Fisiopatologia, Hospital de Clínicas,

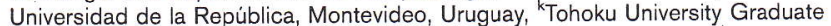
School of Pharmaceutical Sciences and Medicine, Sendai, Japan and Paediatric Nephrology Unit, Department of Paediatrics, Hospital General, University of Valencia, Valencia, Spain

Correspondence to Professor Jan A. Staessen, MD, PhD, FESC, FAHA, Studies Coordinating Centre, Laboratory of Hypertension, University of Leuven, Campus Sint Rafaël, Kapucijnenvoer 35, Block d, Level 00, B-3000 Leuven, Belgium Tel: +32 16347104 ; fax: + 3216347106 ;

e-mail: jan.staessen@med.kuleuven.be; ja.staessen@epid.unimaas.n

Received 18 January 2010 Accepted 20 January 2010

coined the term 'white-coat hypertension' to describe patients whose BP was elevated in the doctor's office, but not during daytime ambulatory BP measurement. For the first time, he assessed the prevalence of white-coat hypertension among 292 borderline hypertensive patients and 42 patients with established hypertension. He applied the 90th percentile of the distribution of awake ambulatory BP in healthy normotensive volunteers as a cutoff point. Using this threshold $(134 / 90 \mathrm{mmHg}), 21 \%$ of the patients with borderline hypertension and $5 \%$ of those with established hypertension had white-coat hypertension. Female sex, short duration of hypertension, and young age were factors associated with white-coat hypertension. Pickering predicted that by combining conventional measurement with ambulatory BP measurement, it would become possible to identify patients at a low risk, in whom the initiation of medical treatment might be questionable, and instead, a longer period of observation might be appropriate [6].

\section{Mechanisms underlying white-coat hypertension}

In 1983, Mancia et al. [7] reported that the doctor's arrival at the bedside induced an instantaneous rise in both systolic and diastolic BP [7]. White-coat hypertension is an alert reaction to the medical environment and to the 
observer, who measures the BP. Thomas Pickering's group assessed office BP, ambulatory BP, and anxiety scores on three separate occasions, 1 month apart in 238 patients. They found that the white-coat effect (WCE) was a conditioned response to the medical environment and the physician's presence, rather than a function of the patient's trait of anxiety (Fig. 1) [8]. As the largest WCE occurred with the physician's measurement, Pickering's group [8], and later Myers et al. [9], proposed that WCE could be minimized by the use of automated BP devices for the measurement of BP in office settings in the absence of an observer. Pickering's group also reported that in a majority of people, worksite BP is consistently higher than home BP [10]. However, the WCE does not reflect generalized hyperactivity, because of the low correlation between the increment in BP the clinic and at work, both relative to the home BP [10].

\section{From distributional to outcome-driven thresholds to diagnose white-coat hypertension}

Inspired by Thomas Pickering's work, an international consortium established the International Database on
Ambulatory Blood Pressure Monitoring and published in 1994 a proposal for operational thresholds to define white-coat hypertension in clinical practice [11]. The database included 7069 recordings contributed by 24 clinical research groups. As few prospective outcome data in relation to the ambulatory BP were available, in 1994 [12-14], the consortium applied the 95th percentile of the ambulatory BP distribution in volunteers who were normotensive on conventional $\mathrm{BP}$ measurement. The proposed systolic/diastolic thresholds were 133/82, $140 / 88$, and $125 / 76 \mathrm{mmHg}$ for the $24-\mathrm{h}$, daytime, and night-time BP, respectively [11]. Similar to Thomas Pickering's publication of 1988 [6], the prevalence of white-coat hypertension in this database was 20-30\%; its probability was greater in women, and it increased with age, but decreased if the patients had higher office BP, and if the diagnosis of hypertension was made after multiple office visits and multiple office BP assessments, or both.

Over the next decade, several prospective outcome studies provided evidence validating the thresholds for

Fig. 1

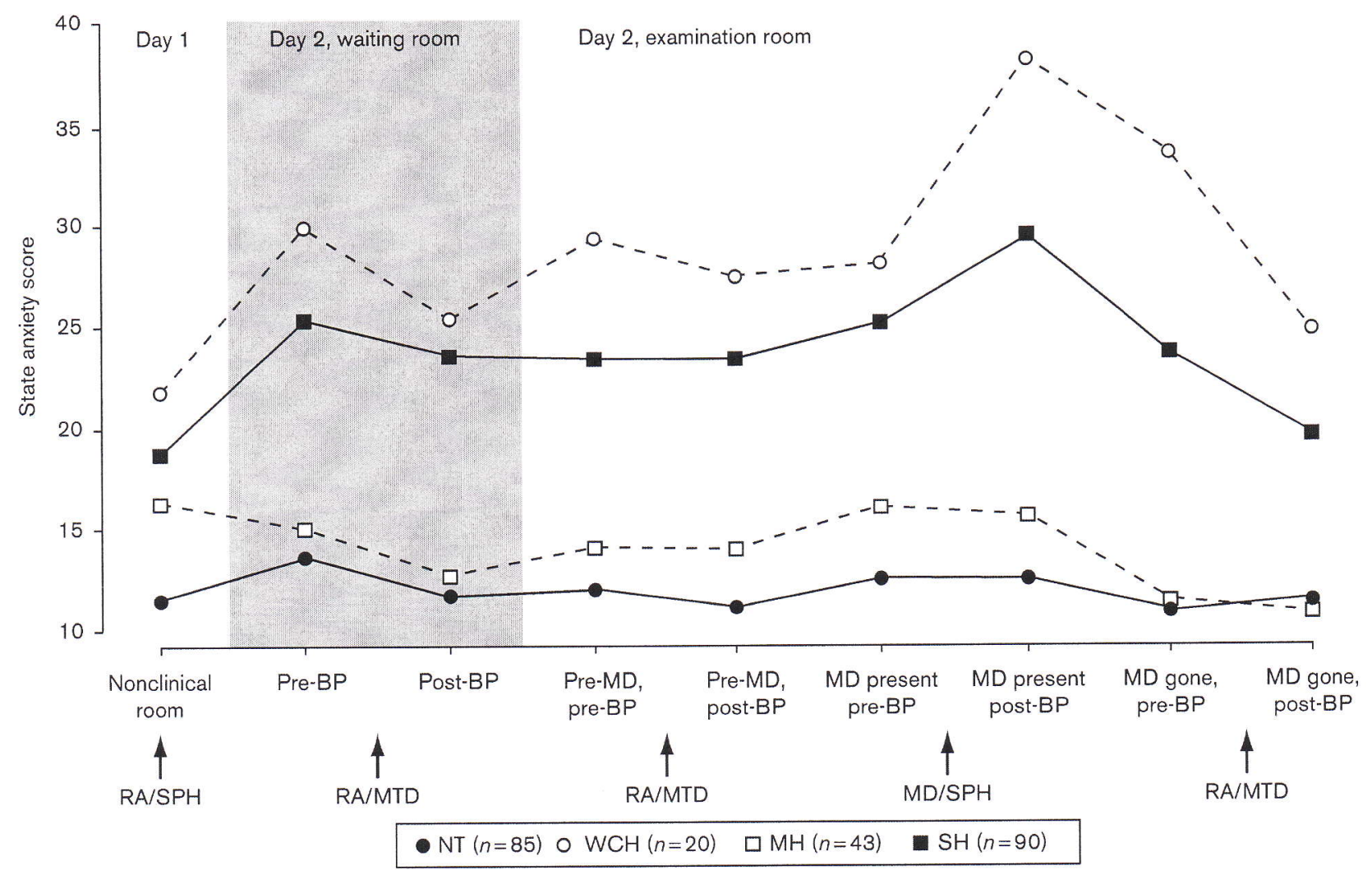

Self-rated anxiety score before (pre) and after (post) blood pressure (BP) measurement in different conditions. On day 1, the research assistant (RA) measured BP outside the medical environment using a mercury sphygmomanometer (SPH). On day 2 , the RA measured BP in the absence of a physician (MD) by manually triggering a device for ambulatory BP measurement (manually triggered device, MTD) first in the waiting room and later in the examination room before and after the MD measured BP using a SPH. Anxiety scores were obtained in normotensive participants (NT) and in patients with white-coat hypertension $(\mathrm{WCH})$, masked hypertension (MH), and sustained hypertension (SH). Reproduced with permission [4]. 
the diagnosis of white-coat hypertension in terms of mortality and morbidity. In the first step, several studies showed that ambulatory $\mathrm{BP}$ was more predictive of an outcome than the BP obtained on conventional measurement [15-19]. In the Systolic Hypertension in Europe Trial (Syst-Eur) [19], to avoid problems with definitions and nomenclature, the WCE was analyzed as a continuous variable. The risk conferred by any level of conventional systolic BP at entry, declined by nearly one-fifth for every $10 \mathrm{mmHg}$ increase in the WCE.

The International Database on Ambulatory blood pressure monitoring in relation to Cardiovascular Outcomes (IDACO) consortium assessed the risk associated with white-coat hypertension compared with normotension and sustained hypertension [19]. This meta-analysis of individual patient data included over 7000 people randomly recruited from four populations, and covered approximately 10 years of follow-up with more than 800 new cardiovascular endpoints. In multivariable-adjusted categorical analyses with normotension as the referent group (conventional BP $<140 / 90 \mathrm{mmHg}$ and daytime ambulatory $\mathrm{BP}<135 / 85 \mathrm{mmHg}$ ), white-coat hypertensive patients (conventional BP $\geq 140 / 90 \mathrm{mmHg}$ and daytime ambulatory $\mathrm{BP}<135 / 85 \mathrm{mmHg}$ ) had a slightly increased risk, but none of the hazard ratios reached significance $(0.63 \geq$ $P \geq 0.09$; Fig. 2). These findings remained consistent if the Cox models were additionally adjusted for the daytime $\mathrm{BP}$ or when a lower cutoff $(<130 / 80 \mathrm{mmHg})$ was used for the daytime BP (Fig. 2) [20]. The same consortium reported outcome-driven thresholds for the ambulatory BP [21]. Approximate thresholds for an optimal level with the lowest cardiovascular risk were $115 / 75,120 / 80$, and $100 / 65 \mathrm{mmHg}$ for the $24-\mathrm{h}$, daytime, and night-time BP, respectively. Rounded thresholds for normal ambulatory BP were 125/75, 130/85, and 110/ $70 \mathrm{mmHg}$, respectively, and those for ambulatory hypertension were $130 / 80,140 / 85$, and $120 / 70 \mathrm{mmHg}$, respectively. These findings suggest that to define white-coat hypertension, lower thresholds might have to be applied than those currently recommended in the guidelines.

\section{Management of white-coat hypertension based on ambulatory monitoring}

The ambulatory BP monitoring and treatment of hypertension (APTH) trial [22] showed that adjustment of antihypertensive treatment based on ABPM instead of conventional sphygmomanometry, may lead to less intensive drug treatment with preservation of BP control, general well-being, and inhibition of left ventricular enlargement. Antihypertensive drug treatment may be postponed in $25 \%$ of the hypertensive patients and multiple-drug treatment may be avoided in $15 \%$ of the hypertensive patients. The APTH results [22] do not imply that patients with white-coat hypertension should be left untreated. However, if no cardiovascular complications are present at diagnosis, treatment could be limited to further follow-up and the implementation of cardiovascular hygienic measures, such as regular exercise, reduction of excessive alcohol and sodium intake, and weight reduction. Initial treatment should also account for other cardiovascular risk factors, such as smoking, hypercholesterolemia, and diabetes mellitus. Whether patients with white-coat hypertension are at a higher risk of developing sustained hypertension remains debatable, although recent evidence supports this contention [23].

\section{Masked hypertension First reports on masked hypertension}

In 2002, Thomas Pickering introduced the term 'masked hypertension' [1] to describe what other researchers called reverse white-coat hypertension [24,25], an elevated ambulatory BP in the presence of a normal office BP. The nomenclature proposed by Pickering [1] emphasizes that patients with masked hypertension are genuinely hypertensive, because of the superiority of ambulatory BP over office BP in predicting cardiovascular events. In this regard, Pickering showed in a cross-sectional study that patients with masked hypertension have more extensive target-organ damage (higher prevalence of carotid plaque and greater left ventricular mass) than true normotensive volunteers (Table 1) [26]. On the basis of this observation, Pickering suggested that masked hypertension should be taken seriously and excluded by ABPM in patients who have a normal clinic BP on repeated office visits, especially among patients with a family history of hypertension, or those with comorbid conditions, such as diabetes mellitus [1]. He did not propose the application of ABPM, to screen for masked hypertension at the population level [1].

\section{Prognosis of masked hypertension: moving from cross-sectional to prospective studies}

Pickering assessed the long-term prognosis of individuals with masked hypertension in an international database $[4,27]$, which included data from his own group ( $n=$ 1296, [27]), the Ohasama population study $(n=1277$, [27]), the Jichi Medical School-ABPM study ( $n=762$, [27]), and the Progetto Ipertensione Umbria Monitoraggio Ambulatoriale (PIUMA; $n=2620$, [27]). In this heterogeneous database [4], 1272 participants had a normal clinic BP $(<140 / 90 \mathrm{mmHg})$, of whom $376 \mathrm{had}$ a high daytime ambulatory $\mathrm{BP}(>135 / 85 \mathrm{mmHg}$ ), whereas other individuals were normotensive by both criteria. The hazard ratio of cardiovascular events in patients with masked hypertension, relative to truly normotensive volunteers was $2.26(P<0.0009)$ [4], thus establishing, in a longitudinal cohort, the higher cardiovascular risk portended by masked hypertension over normotensive volunteers. This finding was later confirmed by the study conducted by the IDACO consortium, which assessed the risk of masked hypertension in 7030 participants randomly 
(a) $130 / 80 \mathrm{mmHg}$

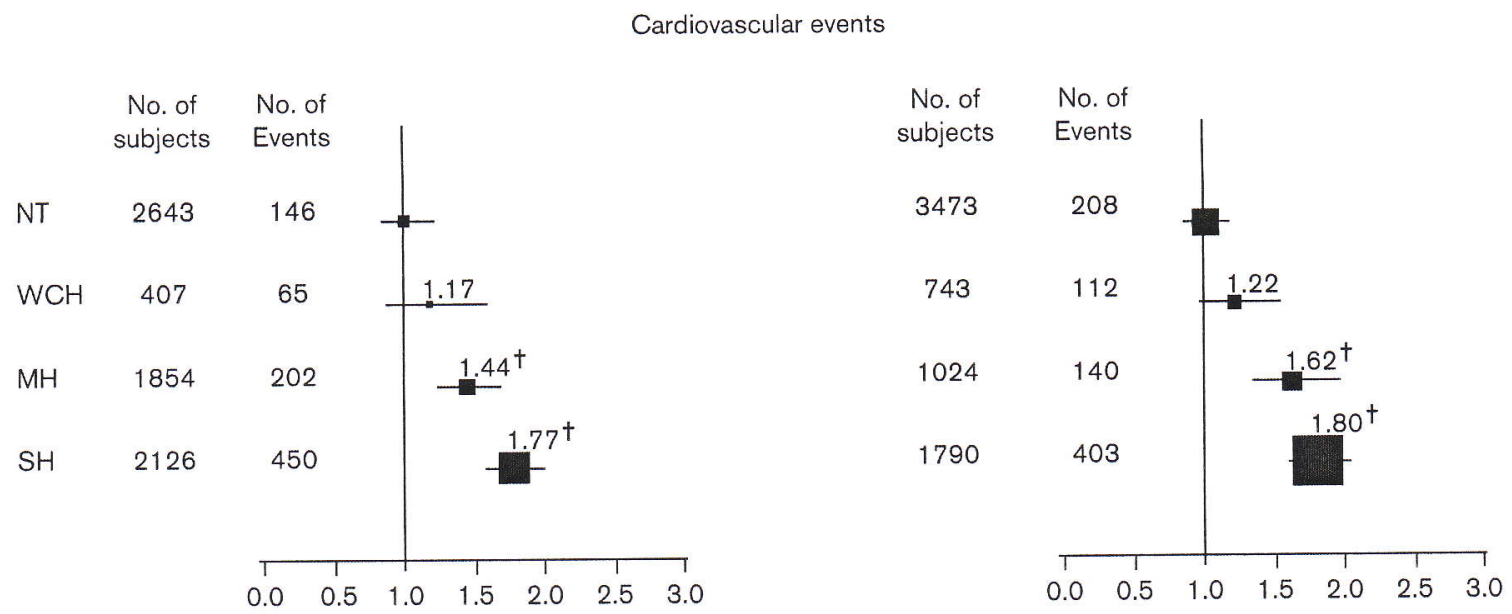

Stroke

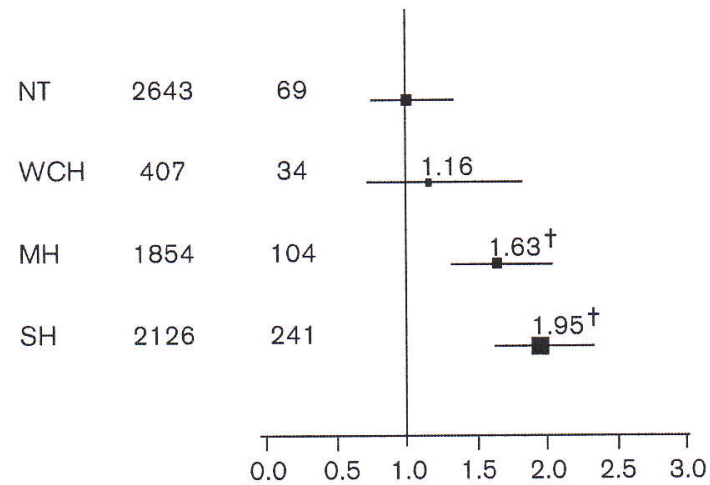

Cardiac events

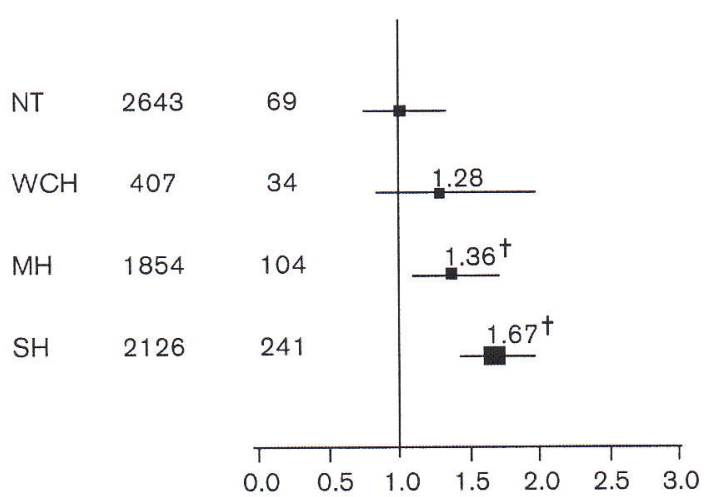

(b) $135 / 85 \mathrm{mmHg}$
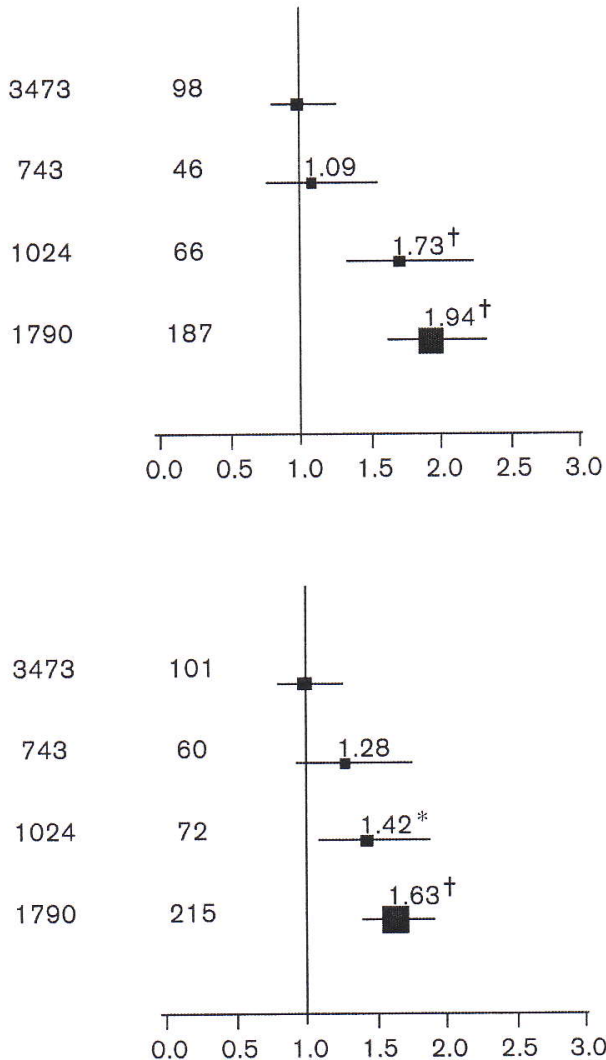

Hazard ratios for cardiovascular events according to the cross-classification of conventional and daytime ambulatory blood pressures. The analyses were based on (a) lower ( $\geq 130 / 80 \mathrm{mmHg}$ ) or (b) higher ( $\geq 135 / 85 \mathrm{mmHg}$ ) cutoff limits for ambulatory hypertension and were adjusted for cohort, sex, age, body mass index, serum cholesterol, smoking and drinking, history of cardiovascular disease, diabetes mellitus, and antihypertensive drug treatment. Squares are proportional to the number of events for each group. Horizontal lines denote the $95 \%$ confidence interval. $\mathrm{MH}$, masked hypertension; NT, normotension; $\mathrm{SH}$, sustained hypertension; $\mathrm{WCH}$, white-coat hypertension. NT is the reference group $\left(* P<0.01 ;{ }^{\dagger} P<0.001\right)$. Reproduced with permission [20] 
Table 1 Left ventricular and carotid arterial structure and function in study patients

\begin{tabular}{|c|c|c|c|}
\hline Measurement & $\begin{array}{l}\text { Patients with true normotension } \\
\qquad(n=234)\end{array}$ & $\begin{array}{l}\text { Patients with masked hypertension } \\
\qquad(n=61)\end{array}$ & $\begin{array}{l}\text { Patients with true hypertension } \\
\qquad(n=64)\end{array}$ \\
\hline \multicolumn{4}{|l|}{ Left ventricle } \\
\hline Interventricular septal thickness $(\mathrm{cm})$ & $0.87 \pm 0.11$ & $0.96 \pm 0.11 * * *$ & $0.97 \pm 0.12 * * *$ \\
\hline Left ventricular internal dimension $(\mathrm{cm})$ & $4.80 \pm 0.44$ & $5.00 \pm 0.44 * *$ & $4.94 \pm 0.50^{*}$ \\
\hline Posterior wall thickness $(\mathrm{cm})$ & $0.79 \pm 0.11$ & $0.90 \pm 0.11^{* * *}$ & $0.92 \pm 0.11 * * *$ \\
\hline Left ventricular mass $(\mathrm{g})$ & $134 \pm 33$ & $169 \pm 40 * * *$ & $166 \pm 43^{* * *}$ \\
\hline Left ventricular mass index $\left(\mathrm{g} / \mathrm{m}^{2}\right)$ & $73 \pm 14$ & $86 \pm 16^{* * *}$ & $90 \pm 18^{* * *}$ \\
\hline Left ventricular mass/height ${ }^{2.7}$ & $32 \pm 6$ & $38 \pm 8 * * *$ & $40 \pm 9 * * *$ \\
\hline Prevalence of LVH $[n(\%)]$ & $1(0.4)$ & $4(7)^{* *}$ & $10(16)^{* * *}$ \\
\hline Relative wall thickness & $0.33 \pm 0.05$ & $0.36 \pm 0.04 * * *$ & $0.37 \pm 0.05 * * *$ \\
\hline \multicolumn{4}{|l|}{ Carotid artery } \\
\hline Wall thickness (mm) & $0.69 \pm 0.16$ & $0.79 \pm 0.18^{* * *}$ & $0.85 \pm 0.19 * * *$ \\
\hline Plaque $[n(\%)]$ & $35(15)$ & $17(28)^{*}$ & $17(27)^{*}$ \\
\hline
\end{tabular}

Values are mean $\pm S D$ or number of participants (\%). LVH indicates left ventricular hypertrophy.

Significance of the difference with the normotensive group: $* P<0.05 ; * * P<0.01 ; * * * P<0.001$.

Reproduced with permission [26].

recruited from four populations [20]. In multivariableadjusted continuous analyses, with true normotension as the reference, the hazard ratios associated with masked hypertension and true hypertension were 1.62 (1.35-1.96; $P<0.0001)$ and $1.80(1.59-2.03 ; P<0.0001)$, respectively (Fig. 2).

Similarly, Lurbe et al. [28] extended Pickering's observation of the higher risk of masked hypertension to adolescents and children. In a nested case-control study of 592 youths aged between 6 and 18 years, they compared echocardiographic left ventricular mass among children with persistent masked hypertension and normotensive controls. They found that participants with masked hypertension had a higher left ventricular mass index and included a higher percentage with a left ventricular mass index above the 95 th percentile in this pediatric population, as compared with normotensive controls [28]. Thus, even in children and adolescents, masked hypertension carries a high risk, being a precursor of sustained hypertension and left ventricular hypertrophy [28].

\section{Diurnal blood pressure variability}

\section{Seminal studies on diurnal blood pressure variability}

In a seminal study of ABPM, Pickering compared the 24-h $\mathrm{BP}$ in normal individuals, patients with borderline hypertension, and those with established hypertension [2]. One of the most striking findings of this study was that the three groups of individuals generally showed similar and parallel changes of their BP during their daily activities. All individuals had their highest BP readings during work or at the clinic, and the lowest readings during sleep (Fig. 3). The noted nocturnal fall in BP during sleep is among the components of $\mathrm{BP}$ variability that have received immense attention from both physiologists and clinicians. In 1988, O'Brien et al. [29] reported for the first time that an abnormal circadian BP profile with decreased night-time dipping might be associated with a higher risk of stroke. Subsequently, numerous studies have corroborated this assertion [30].
Fig. 3

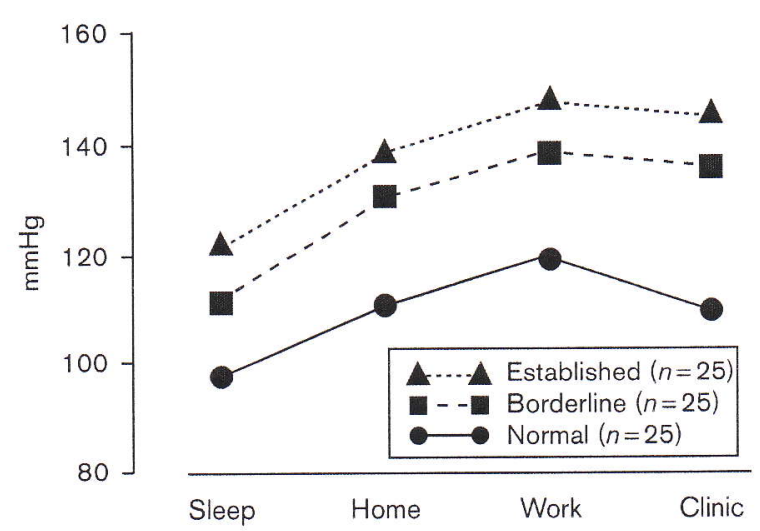

Average values of systolic blood pressure taken under different circumstances with an ambulatory blood pressure recorder in normotensive participants and in patients with borderline hypertension (conventionally measured diastolic blood pressure $90-95 \mathrm{mmHg}$ ) and established hypertension (>95 $\mathrm{mmHg}$ ). Reproduced with permission [2].

\section{Moving from concept to mathematical and outcome-driven criteria for nocturnal dipping}

In an international database established in the 1990s [31], the night-to-day $\mathrm{BP}$ ratio depended less on the BP level than the nocturnal fall in BP did. The ratio may, therefore, be preferable for characterizing dippers as opposed to nondippers. The mathematical definition of nondipping, that is, a night-to-day $\mathrm{BP}$ ratio equal to or higher than unity $(100 \%)$, corresponded nearly with the 95 th percentiles of the ratios in normotensive volunteers. The application of this criterion to both systolic and diastolic BP resulted in an overall prevalence of nondipping of $3.2 \%$, with a distinct age-related increase [31].

The IDACO consortium [32] recently reported risk estimates independently associated with the daytime and night-time BP in 7458 participants enrolled in prospective population studies in six countries. Median follow-up 
was 9.6 years. Adjusted for daytime BP, the night-time BP predicted total $(n=983 ; P<0.0001)$, cardiovascular $(n=387 ; P<0.01)$, and noncardiovascular $(n=560$; $P<0.001)$ mortality. Conversely, adjusted for night-time $\mathrm{BP}$, the daytime BP predicted only noncardiovascular mortality $(P<0.05)$, with lower BP levels being associated with increased risk. Both daytime and night-time BPs consistently predicted all cardiovascular events $(n=943$; $P<0.05)$ and stroke $(n=420 ; P<0.01)$. Adjusted for night-time $\mathrm{BP}$, the daytime $\mathrm{BP}$ lost prognostic significance only for cardiac events $(n=525 ; P \geq 0.07)$. Adjusted for the 24-h BP, the night-to-day BP ratio predicted mortality, but not fatal combined with nonfatal events. Thus, in the IDACO database [32], the predictive accuracy of daytime and night-time BP and the night-to-day BP ratio depended on the disease outcome under study, and differed for fatal outcomes compared with the composite of fatal and nonfatal diseases (Fig. 4). For fatal endpoints, night-time BP performed better than daytime $\mathrm{BP}$, and the night-to-day $\mathrm{BP}$ ratio predicted mortality. By contrast, for fatal combined with nonfatal outcomes, the daytime BP performed equally well as the night-time $\mathrm{BP}$ and the night-to-day $\mathrm{BP}$ ratio lost its prognostic accuracy. Thus, the available evidence supports the concept that the ambulatory BP should be recorded over the entire day, as both the night-time and daytime BP levels carry prognostic information. The 24-h $\mathrm{BP}$ levels rather than the dipping pattern should continue to inform clinical decisions [32].

\section{The morning surge in blood pressure}

Thomas Pickering mentored several young Japanese investigators, who have contributed immensely to the research in ABPM. Examples of his tuition are the studies dealing with the morning surge in $\mathrm{BP}$, that is, the rise in $\mathrm{BP}$ on wake up. Several studies under his supervision showed that it is a predictor of cardiovascular complications. For instance, Japanese hypertensive patients with a mean age of 72 years had a higher risk of multiple brain infarcts and stroke, if the morning surge in systolic BP was above the 90th percentile [33]. Wizner et al. [34] assessed the shortterm and long-term repeatability of the morning surge, using continuous definitions and previously published thresholds. The BP changes in the morning were poorly reproducible, irrespective of whether they were analyzed as a continuous or categorical variable. Nevertheless, prospective outcome studies confirmed that the morning surge in BP is a predictor, albeit weak, of the outcome [33].

The IDACO consortium studied the prognostic significance of the morning BP surge in 5645 participants randomly recruited from eight countries [35]. The sleeptrough and the preawakening morning surge were the differences of the morning $\mathrm{BP}$ with the lowest night-time $\mathrm{BP}$ and the preawakening $\mathrm{BP}$, respectively. Multivariableadjusted hazard ratios were computed, comparing the risk in ethnic-specific and sex-specific deciles of the morning surge relative to the average risk in the whole study population. During follow-up (median, 11.4 years), 785 deaths and 611 fatal and nonfatal cardiovascular events occurred. While accounting for covariables and the nightto-day ratio of systolic pressure, the hazard ratio of all-cause mortality was 1.32 (95\% confidence interval, $1.09-1.59 ; P=0.004)$ in the top decile of the systolic sleep-trough morning surge ( $\geq 37.0 \mathrm{mmHg}$ ). For cardio-

Fig. 4

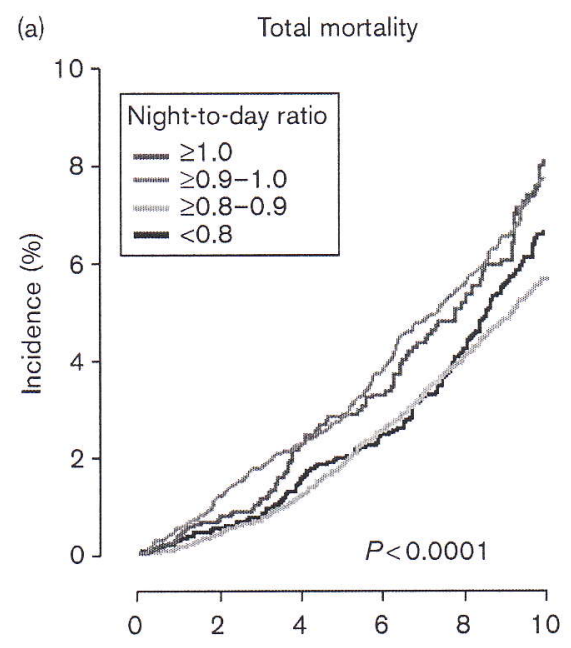

(b)

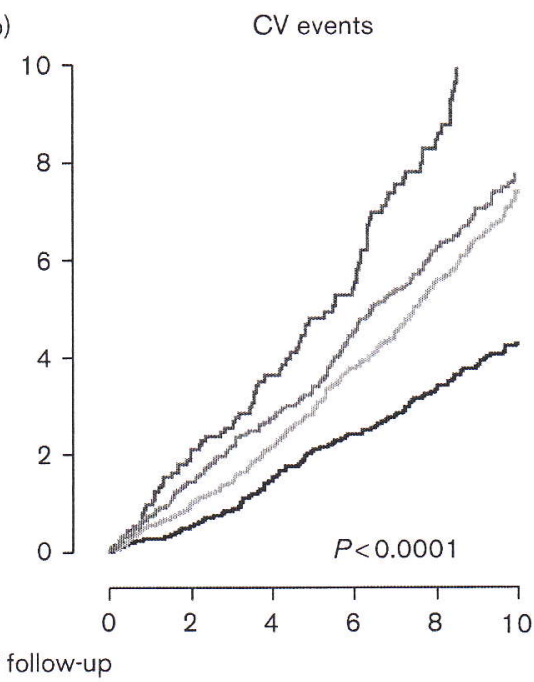

Kaplan-Meier survival function estimates for total mortality (a) and for all cardiovascular (CV) events (b) by category of the night-to-day ratio of systolic blood pressure. Pvalues are for trend across the four categories. Incidence was adjusted for cohort, sex, age, body mass index, smoking and drinking, serum total cholesterol, history of cardiovascular disease, diabetes mellitus, and antihypertensive drug treatment. Reproduced with permission [32]. 
vascular and noncardiovascular deaths, these hazard ratios were $1.18(0.87-1.61 ; P=0.30)$ and $1.42(1.11-1.80$; $P=0.005)$, respectively. For all cardiovascular, cardiac, coronary and cerebrovascular events, the hazard ratios in the top decile of the systolic sleep-trough morning surge were $1.30(1.06-1.60 ; P=0.01), 1.52(1.15-2.00 ; P=$ $0.004), 1.45(1.04-2.03 ; P=0.03)$, and $0.95(0.68-1.32$; $P=0.74$ ), respectively [35]. Analysis of the preawakening systolic morning surge and diastolic morning surge generated consistent results. Thus, a morning surge above the 90 th percentile significantly and independently predicted cardiovascular outcome and might contribute to risk stratification by $\mathrm{ABPM}$ [35].

\section{Self-measurement of blood pressure Self-measurement as an alternative to ambulatory monitoring}

In 1971, investigators from Leuven promoted the use of BP self-measurement at home for clinical research [36]. The development of cheap and properly validated devices for BP self-measurement, over the past 20 years, has made this technique available for clinical application. BP self-monitoring offers several well-recognized advantages over the more complex approach of ambulatory monitoring $[37,38]$. The greater number of readings and the absence of the WCE contribute to a better diagnostic accuracy, compared with conventional sphygmomanometry $[39,40]$. If automated devices are used, self-recorded $\mathrm{BP}$ values are free of observer bias. Moreover, selfmeasurement of BP increases adherence to antihypertensive treatment [41] and allows reducing the number of clinic visits required for the diagnosis and treatment of hypertension [42].

Thomas Pickering repeatedly underlined the importance of the self-monitoring of $\mathrm{BP}$ at home [3-5]. He pointed out that physicians must accept the fact that BP measurement could no longer be restricted to the idiosyncratic environment of the physician's office [3]. In 1984,
Pickering's group compared BP measurements taken in the clinic by physicians and by the patient at home with 24-h ambulatory measurements [43]. Home BP readings were consistently lower than clinic measurements, and correlated more closely with the 24-h ambulatory BP level than the clinic readings (Fig. 5) [43]. Pickering was instrumental in the development of practice guidelines for the use of home BP monitoring in clinical practice through the American Society of Hypertension, the European Society of Hypertension, and the American Heart Association [5,44,45].

\section{Mathematical and outcome-driven thresholds for the self-measured blood pressure}

In an attempt to define diagnostic thresholds for the self-measured BP, we performed two meta-analyses, in collaboration with a large number of researchers [46,47], which were based on aggregate data extracted from published articles [46] and on individual patient data that were made available to the International Database of Self-Recorded Blood Pressures, respectively [47].

In 1998, we reviewed 17 studies including a total of 5422 participants [46]. Within each study, we computed an operational threshold for the self-measured BP separating normotension from hypertension either by the mean +2 standard deviations or by the 95 th percentile of the selfrecorded $\mathrm{BP}$ in participants who were normotensive according to their office BP. For the sake of comparability with the contemporary literature, we also extracted the thresholds derived by the regression approach [48] or the percentile method [49,50], from published studies. The former consists of calculating the regression line between the self-recorded BP and the clinic BP in individual patients to estimate the self-recorded BP that corresponds with a clinic BP of $140 \mathrm{mmHg}$ systolic or $90 \mathrm{mmHg}$ diastolic. The percentile method first involves the calculation of the percentile of the clinic BP that corresponds to $140 \mathrm{mmHg}$ systolic or $90 \mathrm{mmHg}$ diastolic,

Fig. 5

(a)

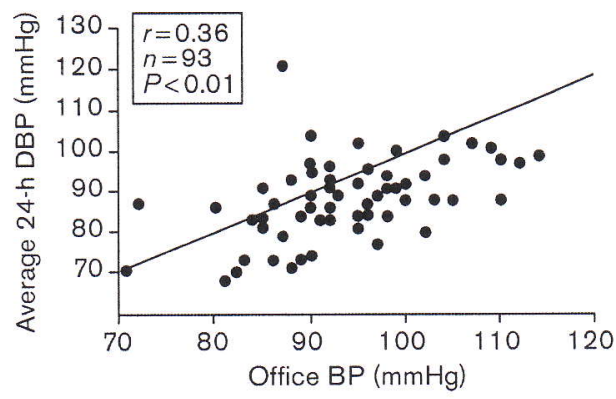

(b)

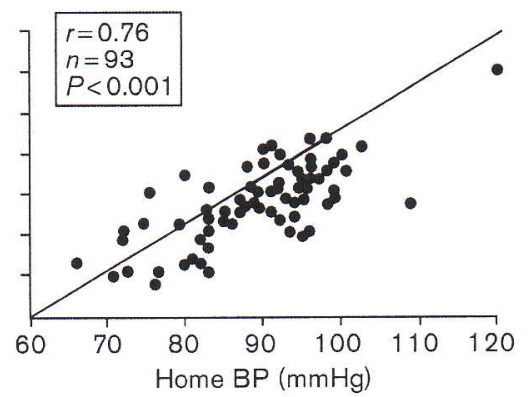

(a) Office diastolic blood pressure vs. average 24-h diastolic blood pressure recordings; (b) self-measured diastolic blood pressure at home vs. average 24-h diastolic blood pressure recordings. Lines of identity have been drawn. Reproduced with permission [43]. 


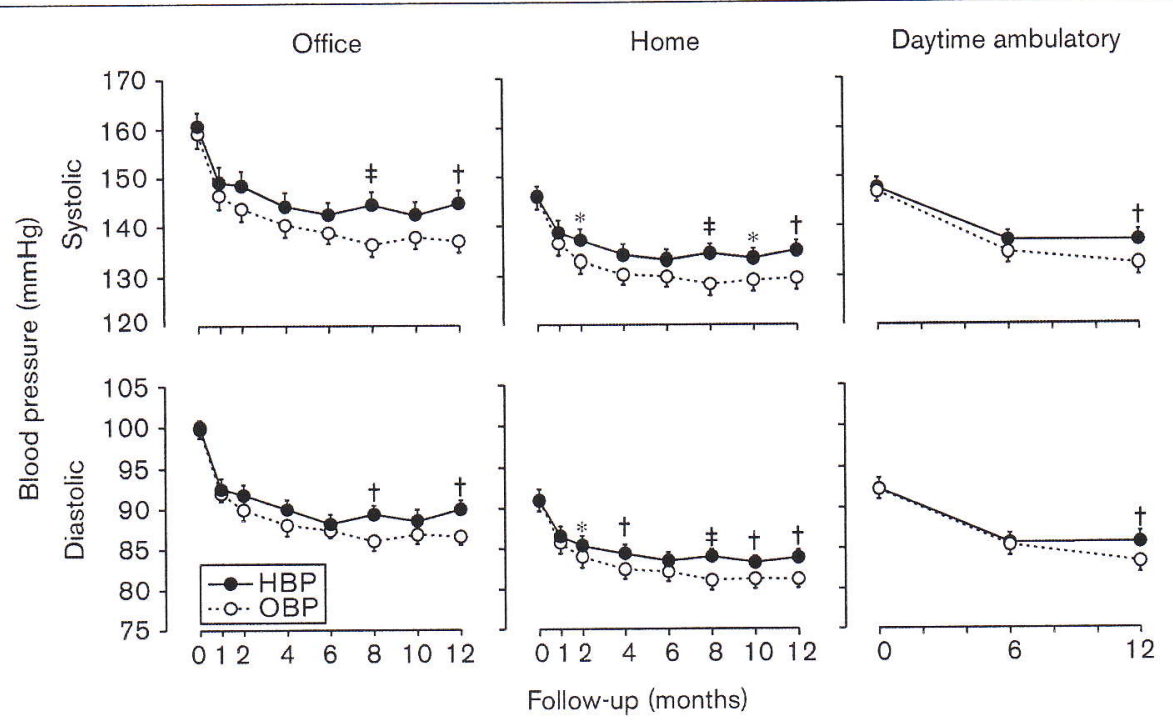

Mean systolic and diastolic blood pressures measured at physician's office, at the patient's home, and by daytime ambulatory monitoring. Error bars indicate SEs. $P$ values are for differences between patients randomized to treatment based on blood pressure measurement at the physician's office vs. at home. Significance of the between-group difference: ${ }^{*} P \leq 0.05 ;{ }^{\ddagger} P \leq 0.01 ;{ }^{\ddagger} P \leq 0.001$. HBP, home blood pressure; OBP, office blood pressure. Reproduced with permission [51].

and later the determination of the self-recorded BP that ranks at the same percentile value [46]. The reference values for the self-recorded systolic/diastolic BP as derived from the mean +2 standard deviations (137/ $89 \mathrm{mmHg})$ and the $95 \mathrm{th}$ percentile $(135 / 86 \mathrm{mmHg})$ of the distribution in normotensive volunteers were concordant within $2 \mathrm{mmHg}$ systolic and $3 \mathrm{mmHg}$ diastolic. The cutoff points derived using the regression and percentile methods were considerably lower, 129/84 and $125 / 79 \mathrm{mmHg}$, respectively [46].

Thirteen research groups contributed individual data of 4668 untreated participants to the International Database [47], of which 2401 were normotensive on office measurement. The mean self-recorded BP in normotensive participants averaged $115.4 \mathrm{mmHg}$ systolic and $70.7 \mathrm{mmHg}$ diastolic. The 95 th percentiles of their self-recorded BPs were $136 \mathrm{mmHg}$ systolic and $86 \mathrm{mmHg}$ diastolic in the morning, 139 and $86 \mathrm{mmHg}$ in the evening, and 137 and $85 \mathrm{mmHg}$ over the whole day. Of 1773 patients with definite systolic hypertension on office measurement, $16 \%$ had a self-measured systolic BP below $137 \mathrm{mmHg}$ (the 95th percentile of the self-measured systolic pressure in normotensive participants). Similarly, 25\% of those with definite diastolic hypertension had a self-measured diastolic BP below $85 \mathrm{mmHg}$ (the 95th percentile of the self-measured diastolic pressure in normotensive participants). The probability that participants with definite hypertension had a self-measured BP below these thresholds (white-coat hypertension) was $34 \%$ (diastolic) to $62 \%$ (systolic) greater in women than in men. It was two-to-three-folds greater if fewer than three office BP readings had been averaged to diagnose hypertension, and it increased by $50 \%$ (diastolic) to $126 \%$ (systolic) if the self-measured BP had been measured on more than 3 days as opposed to a fewer number of days. In contrast, for every $10-\mathrm{mmHg}$ increment in the systolic office BP, the probability of isolated office systolic hypertension decreased by $35 \%$; for every $5-\mathrm{mmHg}$ increment in the diastolic office $\mathrm{BP}$, the probability of isolated office diastolic hypertension decreased by $36 \%$. Finally, the probability of isolated office systolic hypertension decreased by $31 \%$ for every 10 -year increment in age [47].

\section{Management of hypertension based on self-measurement}

In the Treatment of hypertension based on Home or Office blood Pressure (THOP) trial [51], antihypertensive drug treatment was adjusted in a stepwise manner based on either the self-measured diastolic BP at home (an average of six measurements each day, during 1 week; 203 patients) or the average of three sitting diastolic readings at the doctor's office (197 patients). If the diastolic BP guiding treatment was above $(>89 \mathrm{mmHg}$ ), at $(80-89 \mathrm{mmHg})$, or below $(<80 \mathrm{mmHg})$ the target, one physician blinded to the patients' randomization, intensified antihypertensive treatment, left it unchanged or reduced it, respectively.

The target BP was the same in the two treatment groups. At the end of the study (median follow-up, 350 days), more patients who were randomized to self-measurement had stopped antihypertensive treatment (25.6 vs. $11.3 \%$; $P=0.14)$. The final office, home, and 24-h ambulatory BPs were higher $(P<0.001)$ in patients randomized to 
self-measurement than in those treated according to the office BP. The baseline-adjusted systolic/diastolic differences between these two groups averaged: office, $6.8 /$ $3.5 \mathrm{mmHg}$; home, $4.9 / 2.9 \mathrm{mmHg}$; and 24-h ambulatory, 4.9/2.9 $\mathrm{mmHg}$, respectively (Fig. 6). Left ventricular mass and reported symptoms were similar in the two groups [51]. The THOP trial [51] confirmed that the cutoff limit for the diastolic BP should be lower for home than office measurement.

In the randomized Home versus office blood pressure MEasurement: Reduction of Unnecessary treatment study (HOMERUS) [52,53], the office BP and the selfmeasured BP guided antihypertensive drug treatment in the control and experimental group, respectively. In contrast to the THOP trial [51], HOMERUS patients randomized to office $\mathrm{BP}$ measurement, did not record their BP at home [52]. The patients underwent ABPM at entry and at closeout. By using a standardized treatment schedule, the investigators had to reach in their patients the target BP levels of $120-139 \mathrm{mmHg}$ systolic and $80-89 \mathrm{mmHg}$ diastolic. This goal was similar in both treatment groups [53]. A blinded physician at the coordinating center took the treatment decisions. The stated hypothesis [52] was that at the end of the 1-year follow-up period, patients in both groups would have the same BP, at the expense of more medication in the office BP group.

The patients randomized to self-measurement $(n=216)$ used less medication than those $(n=214)$ allocated to office BP measurement (1.47 vs. 2.48 drug steps; $P<0.001)$ with lower costs $(\$ 3222$ vs. $\$ 4420$ per 100 patients per month; $P<0.001$ ), but without significant differences in systolic and diastolic $\mathrm{BP}$ in office measurement (1.6/1.0 mmHg; $P=0.25 / 0.20)$, in changes in left ventricular mass index $\left(-6.5\right.$ vs. $\left.-5.6 \mathrm{~g} / \mathrm{m}^{2} ; P=0.72\right)$, or in median urinary microalbumin excretion $(-1.7$ vs. $-1.5 \mathrm{mg} / 24 \mathrm{~h}$; $P=0.87)$. Nevertheless, the $24-\mathrm{h}$ ambulatory BP was higher (125.9/77.2 vs. $123.8 / 76.1 \mathrm{mmHg} ; P<0.05 / 0.05)$ in the self-measurement than the office group [53].

\section{Perspectives}

We showed that Pickering's work lies at the heart of many subsequent studies on white-coat hypertension and masked hypertension, diurnal BP variability, and the use of the self-measured BP. His concepts have now been validated in terms of cardiovascular outcomes and are routinely being used in day-to-day clinical practice. This is by no means the end of a fascinating stream of research. For instance, randomized clinical trials should test the hypothesis that reacting immediately to selfmeasured BP by means of telemedicine or that restoring the diurnal BP profile might be beneficial in terms of the prevention of cardiovascular morbidity and mortality. In this respect, Thomas G. Pickering's premature death might not be the end of an era, but might provide the motivation to continue his work, in the interest of many patients.

\section{Acknowledgements}

The European Union (Grants IC15-CT98-0329-EPOGH, LSHM-CT-2006-037093, and HEALTH-F4-2007-201550), the Fonds voor Wetenschappelijk Onderzoek Vlaanderen (Ministry of the Flemish Community, Brussels, Belgium; Grants G.0575.06 and G.0734.09), and the Katholieke Universiteit Leuven (Grants OT/00/25 and OT/05/49) gave support to the Studies Coordinating Centre in Leuven. The European Union (Grants LSHM-CT-2006037093 and HEALTH-F4-2007-201550) also supported the research groups in Krakow and Shanghai. The authors acknowledge the secretarial assistance of Ms Sandra Covens and Ms Ya Zhu (Studies Coordinating Centre, University of Leuven, Leuven, Belgium).

\section{References}

1 Pickering TG, Davidson K, Gerin W, Schwartz JE. Masked hypertension. Hypertension 2002; 40:795-796.

2 Pickering TG, Harshfield GA, Kleinert HD, Blank S, Laragh JH. Blood pressure during normal daily activities, sleep, and exercise. Comparison of values in normal and hypertensive subjects. JAMA 1982; 247:992-996.

3 Pickering TG, Harshfield GA, Devereux RB, Laragh JH. What is the role of ambulatory blood pressure monitoring in the management of hypertensive patients? Hypertension 1985; 7:171-177.

4 Pickering TG, Gerin W, Schwartz JE, Spruill TM, Davidson KW. Franz Volhard lecture: should doctors still measure blood pressure? The missing patients with masked hypertension. J Hypertens 2009; 26:2259-2267.

5 Pickering TG, Houston Miller N, Ogedegbe G, Krakoff LR, Artinian NT, Goff D. Call to action on use and reimbursement for home blood pressure monitoring. A joint scientific statement from the American Heart Association, American Society of Hypertension, and Preventive Cardiovascular Nurses Association. Hypertension 2008; 52:10-29.

6 Pickering TG, James GD, Boddie C, Harshfield GA, Blank S, Laragh JH. How common is white coat hypertension? JAMA 1988; 259 225-228.

7 Mancia G, Bertinieri G, Grassi G, Parati G, Pomidossi G, Ferrari A, et al. Effects of blood pressure measurement by the doctor on patient's blood pressure and heart rate. Lancet 1983; ii:695-698.

8 Ogedegbe G, Pickering TG, Clemow L, Chaplin W, Spruill TM, Albanese $\mathrm{GM}$, et al. The misdiagnosis of hypertension. The role of patient anxiety. Arch Intern Med 2008; 168:2459-2465.

9 Myers MG, Valdivieso M, Kiss A. Use of automated office blood pressure measurement to reduce the white coat response. $J$ Hypertens 2009; 27:280-286.

10 Harshfield GA, Pickering TG, Kleinert HD, Blank S, Laragh JH. Situational variations of blood pressure in ambulatory hypertensive patients. Psychosom Med 1982; 44:237-245.

11 Staessen JA, O'Brien ET, Amery AK, Atkins N, Baumgart $P$, De Cort $P$ et al. Ambulatory blood pressure in normotensive and hypertensive subjects: results from an international database. J Hypertens 1994; 12 (Suppl 7):S1-S12.

12 Perloff $\mathrm{D}$, Sokolow $\mathrm{M}$, Cowan $\mathrm{R}$. The prognostic value of ambulatory blood pressures. JAMA 1983; 249:2792-2798.

13 Perloff D, Sokolow M, Cowan RM, Juster RP. Prognostic value of ambulatory blood pressure measurements: further analyses. I Hypertens 1989; 7 (Suppl 3):S3-S10.

14 Mann S, Millar Craig MW, Raftery EB. Superiority of 24-h measurement of blood pressure over clinic values in determining prognosis in hypertension. Clin Exp Hypertens 1985; A7:279-281.

15 Khattar RS, Senior R, Lahiri A. Cardiovascular outcome in white-coat versus sustained mild hypertension. A 10-year follow-up study. Circulation 1998; 98:1892-1897.

16 Khattar RS, Swales JD, Banfield A, Dore C, Senior R, Lahiri A. Prediction of coronary and cerebrovascular morbidity and mortality by direct continuous ambulatory blood pressure monitoring. Circulation 1999; 100:1071-1076. 
17 Ohkubo T, Imai $Y$, Tsuji I, Nagai $\mathrm{K}$, Ito $\mathrm{S}$, Satoh $\mathrm{H}$, et al. Reference values for 24-h ambulatory blood pressure monitoring based on a prognositic criterion. The Ohasama Study. Hypertension 1998; 32:255-259.

18 Redón J, Campos C, Narciso ML, Rodicio JL, Pascual JM, Ruilope LM Prognostic value of ambulatory blood pressure monitoring in refractory hypertension. A prospective study. Hypertension 1998; 31:712-718.

19 Staessen JA, Thijs L, Fagard R, O'Brien ET, Clement D, De Leeuw PW, et al. Predicting cardiovascular risk using conventional versus ambulatory blood pressure in older patients with systolic hypertension. JAMA 1999; 282:539-546.

20 Hansen TW, Kikuya M, Thijs L, Björklund-Bodegård K, Kuznetsova T, Ohkubo $T$, et al. Prognostic superiority of daytime ambulatory over conventional blood pressure in four populations: a meta-analysis of 7030 individuals. J Hypertens 2007; 25:1554-1564.

21 Kikuya $M$, Hansen TW, Thijs $L$, Björklund-Bodegård $K$, Kuznetsova $T$, Ohkubo $\mathrm{T}$, et al. Diagnostic thresholds for ambulatory blood pressure monitoring based on 10-year cardiovascular risk. Circulation 2007; 115:2145-2152.

22 Staessen JA, Byttebier G, Buntinx F, Celis H, O'Brien ET, Fagard R, et al. Antihypertensive treatment based on conventional or ambulatory blood pressure measurement. A randomized controlled trial. JAMA 1997; 278:1065-1072.

23 Mancia G, Bombelli M, Facchetti R, Madotto F, Quarti-Trevano F, Polo Friz $\mathrm{H}$, et al. Long-term risk of sustained hypertension in white-coat or masked hypertension. Hypertension 2009; 54:226-232.

24 Mancia G. Reversed white-coat hypertension: definition, mechanisms and prognostic implications. J Hypertens 2002; 20:579-581.

25 Wing LMH, Brown MA, Beilin LJ, Ryan P, Reid CM, on behalf of the ANBP2 Management Committee and Investigators. Reverse white-coat hypertension in older hypertensives. J Hypertens 2002; 20:639-644.

26 Liu JE, Roman MJ, Pini R, Schwartz JE, Pickering TG, Devereux RB. Cardiac and arterial target organ damage in adults with elevated ambulatory and normal office blood pressure. Ann Intern Med 1999; 131:564-572.

27 Verdecchia P, Reboldi GP, Angeli F, Schillaci G, Schwartz JE, Pickering TG et al. Short- and long-term incidence of stroke in white-coat hypertension. Hypertension 2005; 45:203-208

28 Lurbe E, Torro L, Alvarez V, Nawrot T, Paya R, Redón J, et al. Prevalence, persistence, and clinical significance of masked hypertension in youth Hypertension 2005; 45:493-498.

29 O'Brien E, Sheridan J, O'Malley K. Dippers and non-dippers. Lancet 1988 ; ii:397.

30 Parati G, Staessen JA. Day-night blood pressure variations: mechanisms reproducibility and clinical relevance. $\int$ Hypertens 2007; 25:2377-2380.

31 Staessen JA, Bieniaszewski L, O'Brien E, Gosse P, Hayashi H, Imai Y, et al. Nocturnal blood pressure fall on ambulatory monitoring in a large international database. Hypertension 1997; 29:30-39.

32 Boggia J, Li Y, Thijs L, Hansen TW, Kikuya M, Björklund-Bodegård $K$, et al. Prognostic accuracy of day versus night ambulatory blood pressure: a cohort study. Lancet 2007; 370:1219-1229.

33 Kario K, Pickering TG, Umeda Y, Hoshide S, Hoshide Y, Morinari M, et al. Morning surge in blood pressure as predictor of silent and clinical cerebrovascular disease in elderly hypertensives: a prospective study. Circulation 2003; 107:1401-1406.

34 Wizner B, Dechering DG, Thijs L, Atkins N, Fagard R, O'Brien E, et al. Short-term and long-term reproducibility of the morning blood pressure in older patients with isolated systolic hypertension. $J$ Hypertens 2008; 26:1328-1335.

35 Li Y, Hansen TW, Kikuya M, Boggia J, Richart T, Metoki H, et al. Prognostic value of the morning blood pressure surge in 5645 subjects from 8 populations. Hypertension 2010; (in press).

36 Joossens JV, Willems J, Claessens J, Claes J, Lissens W. Sodium and hypertension. In: Fidanza F, Keys A, Ricci G, Somogyi JC, editors. Nutrition and cardiovascular diseases. Rome, Italy: Morgagni Edizioni Scientifiche; 1971. pp. 91-110.

37 Celis $H$, De Cort $P$, Fagard R, Thijs L, Staessen JA. For how many days should blood pressure be measured at home in older patients before steady levels are obtained? J Hum Hypertens 1997; 11:673-677.

38 Stergiou G, Skeva II, Zourbaki AS, Mountokalakis TD. Self monitoring of blood pressure at home: how many measurements are needed? $J$ Hypertens 1998; 16:725-731.

39 O'Brien E, Fitzgerald D, O'Malley K. Comparison of clinic, home and ambulatory blood pressure measurement. J Ambul Monitoring 1988; 1:285-291.

40 Cottier C, Julius S, Gajendragadkar SV, Schork MA. Usefulness of home BP determination in treating borderline hypertension. JAMA 1982; 248:555-558.

41 Carnahan JE, Nugent CA. The effects of self-monitoring by patients on the control of hypertension. Am J Med Sci 1975; 269:69-73.

42 Chatellier G, Dutrey-Dupagne C, Vaur L, Zannad F, Genès N, Elkik F, et al. Home self blood pressure measurement in general practice. The SMART Study. Am J Hypertens 1996; 9:644-652.

43 Kleinert HD, Harshfield GA, Pickering TG, Devereux RB, Sullivan PA, Marion RM, et al. What is the value of home blood pressure measurement in patients with mild hypertension? Hypertension 1984; 6:574-578.

44 Pickering TG, Hall JE, Appel LJ, Falkner BE, Graves J, Hill MN, et al. Recommendations for blood pressure measurement in humans and experimental animals. Part 1: blood pressure measurement in humans. A statement for professionals from the Subcommittee of Professional and Public Education of the American Heart Association Council on High Blood Pressure Research. Hypertension 2005; 45:142-161.

45 Parati G, Stergiou GS, Asmar R, Bilo G, de Leeuw P, Imai Y, et al. European Society of Hypertension guidelines for blood pressure monitoring at home: a summary report of the second international consensus conference on home blood pressure monitoring. J Hypertens 2008; 26:1505-1526.

46 Thijs L, Staessen JA, Celis H, De Gaudemaris R, Imai Y, Julius $S$, et al. Reference values for self-recorded blood pressure: a meta-analysis of summary data. Arch Intern Med 1998; 158:481-488.

47 Thijs L, Staessen JA, Celis H, Fagard R, De Cort P, De Gaudemaris R, et al. The International Database of Self-recorded Blood Pressures in normotensive and untreated hypertensive subjects. Blood Press Monit $1999 ; 4: 77-86$

48 Mancia G, Sega R, Bravi C, Di Vito G, Valagussa F, Cesana G, et al. Ambulatory blood pressure normality: results from the PAMELA study. $J$ Hypertens $1995 ; 13: 1377-1390$.

49 De Gaudemaris R, Chau NP, Mallion JM, for the Groupe de la Mesure French Society of Hypertension. Home blood pressure: variability, comparison with office readings and proposal for reference values. $J$ Hypertens $1994 ; 12: 831-838$.

50 Weisser B, Grüne S, Burger R, Blickenstorfer H, Iseli J, Michelsen SH, et al. The Dübendorf Study: a population-based investigation on normal values of blood pressure self-measurement. J Hum Hypertens 1994; 8:227-231.

51 Staessen JA, Den Hond E, Celis H, Fagard R, Keary L, Vandenhoven G, et al. Antihypertensive treatment based on blood pressure measurement at home or in the physician's office: a randomized controlled trial. JAMA 2004; 291:955-964

52 Verberk WJ, Kroon AA, Kessels AG, Dirksen C, Nelemans PJ, Lenders JW, et al. Home Versus Office Blood Pressure Measurements: Reduction of Unnecessary Treatment Study: rational and study design of the HOMERUS trial. Blood Press 2003; 12:326-333.

53 Verberk WJ, Kroon AA, Lenders JWM, Kessels AGH, van Montfrans GA, Smit AJ, et al. Self-measurement of blood pressure at home reduces the need for antihypertensive drugs: a randomized, controlled trial. Hypertension 2007; 50:1019-1025. 